\title{
Desenvolvimento e crescimento econômico das macrorregiões de Mato Grosso nos anos 2005 e 2013
}

\author{
Development and economic growth of the macroregions of Mato Grosso in the \\ years 2005 and 2013
Développement et la croissance économique du Mato Grosso des macro- régions en 2005 et 2013

\section{Desarrollo y el crecimiento económico de Mato Grosso de las macrorregiones en 2005 y 2013}

\author{
Nagela Bueno Santos ${ }^{1}$ \\ Alexandre Magno de Melo Faria ${ }^{1}$ \\ Dilamar Dallemole ${ }^{1}$ \\ José Ramos Pires Manso²
}

Recebido em 21/11/2016; revisado e aprovado em 12/06/2017; aceito em 18/06/2017

DOI: http://dx.doi.org/10.20435/inter.v18i3.1442

\begin{abstract}
Resumo: Busca-se analisar o nível de desenvolvimento e crescimento econômico das macrorregiões de Mato Grosso nos anos 2005 e 2013. Os indicadores e testes apresentados demonstram que a expansão econômica nas regiões não foi acompanhada de melhorias significativas nos índices de educação, saúde e emprego e renda. A pesquisa evidencia que, no período analisado, não ocorreu o efeito de transbordamento entre crescimento e desenvolvimento defendido na literatura econômica neoclássica.
\end{abstract}

Palavras-chave: crescimento econômico; desenvolvimento socioeconômico; desenvolvimento de Mato Grosso.

\begin{abstract}
The objective is to analyze the level of development and economic growth of the macroregions of Mato Grosso in the years 2005 and 2013. The indicators and tests presented show that the economic expansion in the regions was not accompanied by significant improvements in the indices of education, health and employment and income. The research shows that during the analyzed period there was no overflow effect between growth and development in the neoclassical economic literature.
\end{abstract}

Key words: economic growth; socioeconomic development; development of Mato Grosso.

Résumé: L'objectif est d'analyser le niveau de développement et la croissance économique du Mato Grosso des macro-régions en 2005 et 2013. Les indicateurs présentés et les tests démontrent que l'expansion économique dans les régions n’a pas été accompagnée par des améliorations significatives aux niveaux de l'éducation, de la santé et de l'emploi et le revenu. La recherche montre que, dans la période analysée, il n'y a pas eu d'effet de transbordement entre la croissance et le développement préconisée dans la littérature économique néoclassique.

Mots-clés: croissance économique; développement socio-économique; développement du Mato Grosso.

Resumen: El objetivo es analizar el nivel de desarrollo y el crecimiento económico de Mato Grosso de las macrorregiones en 2005 y 2013. Los indicadores presentados y las pruebas demuestran que la expansión económica en las regiones no estuvo acompañado de mejoras significativas en los niveles de educación, salud y empleo y los ingresos. La investigación muestra que en el período analizado no era el efecto de contagio entre el crecimiento y el desarrollo defendido en la literatura económica neoclásica.

Palabras clave: crecimiento económico; desarrollo socioeconómico; desarrollo de Mato Grosso.

\footnotetext{
${ }^{1}$ Universidade Federal de Mato Grosso, Cuiabá, Mato Grosso, Brasil.

${ }^{2}$ Universidade da Beira Interior, Covilhã, Portugal.
} 


\section{INTRODUÇÃO}

A relação entre crescimento econômico e desenvolvimento é amplamente debatida na literatura econômica e passou por diversas modificações ao longo do tempo. Desde as primeiras contribuições sistemáticas, no século XVIII, até meados do século XX, crescimento econômico e desenvolvimento foram tratados como sinônimos ou como uma relação de causa e efeito. Contribuições mais recentes, no entanto, estabelecem fortes críticas às teorias que preconizam o papel do crescimento no processo de desenvolvimento.

A presente pesquisa objetiva estabelecer uma análise sobre a relação entre o crescimento econômico e o desenvolvimento do território mato-grossense, à luz das contribuições teóricas mais recentes sobre o tema. Além do nível geográfico agregado (estadual), subdividiu-se a análise por macrorregiões com intuito de verificar se os processos aconteceram de maneira homogênea ou heterogênea no espaço e qual a dinâmica observada em cada uma delas. Neste artigo, a designação espacial "macrorregiões" passa a ser tratada, por simplificação, apenas como "regiões". As regiões, sete no total, foram definidas de acordo com a divisão territorial utilizada pelo Instituto Mato-grossense de Economia Agropecuária (IMEA), por segmentar o estado sob o ponto de vista agroeconômico ${ }^{3}$.

A abordagem do crescimento econômico foi realizada por meio da apresentação e análise dos principais indicadores da economia do estado e suas regiões nos anos de 2005 e 2013. A medida utilizada para análise do desenvolvimento foi o Índice FIRJAN de Desenvolvimento Municipal (IFDM), referentes aos mesmos anos. A verificação em níveis de estado ou regiões se dá por meio da agregação dos indicadores econômicos e pela obtenção de médias dos índices municipais que compõe cada território. As médias são obtidas conjuntamente com a aplicação do teste não-paramétrico de Mann-Whitney, que testa se a evolução do índice em determinada região/estado é estatisticamente significativa.

\subsection{A relação entre crescimento econômico e desenvolvimento}

O debate sobre o real papel do crescimento econômico no processo de desenvolvimento pode ser considerado recente, à medida que só começou a ganhar força após a segunda metade do século XX. A razão é simples, todos os países que haviam se desenvolvido até 1960 o haviam feito por meio da industrialização. Ocorre, no entanto, que, a partir da década de 1950, tornam-se perceptíveis países que haviam buscado trilhar o caminho da industrialização, mas que não obtiveram o mesmo resultado, como é o caso do Brasil (VEIGA, 2010).

Uma das implicações de se denotar o desenvolvimento como resultado do processo de industrialização é a adoção, nas teorias econômicas predominantes, do produto per capita como medida do progresso social, ou seja, não havia diferenciação entre crescimento econômico e desenvolvimento. Schumpeter (1997) registrou uma das primeiras iniciativas teóricas ao introduzir a ideia de que o crescimento econômico seria condição necessária, mas não suficiente para levar ao desenvolvimento.

\footnotetext{
${ }^{3}$ Outros recortes espaciais comumente utilizados são: a do Instituto Brasileiro de Geografia e Estatística (IBGE) que subdivide o estado em cinco mesorregiões; e a da Secretaria de Estado de Planejamento e Coordenação Geral, que divide o território mato-grossense em doze regiões de planejamento, produto dos estudos do projeto de Zoneamento Socioeconômico-Ecológico (ZSEE).
} 
O desenvolvimento, tendo o industrialismo como propulsor e a renda per capita como medida, foi predominante no pensamento econômico até fim do século XX. No entanto diversas contestações a esse pensamento surgiram, com destaque para as tentativas de resgatar a relação entre economia e ética e de introduzir a questão ambiental nas análises. Tais esforços tiveram dois principais motivadores.

Por um lado, a influência do Programa das Nações Unidas para o Desenvolvimento (PNUD) e a publicação do primeiro "Relatório do Desenvolvimento Humano", em 1990, que acabou tornando-se a base para criação, em 1993, do Índice de Desenvolvimento Humano (IDH). E por outro, as consequências do processo de industrialização que colocou em evidência problemas da escassez de recursos naturais finitos e de poluição, passando a tornar-se agenda de encontros e conferências internacionais a partir da década de 1970 (VEIGA, 2010).

A criação do IDH foi resultado da busca por uma alternativa à renda per capita como medida de desenvolvimento. O índice, composto pela compilação de indicadores de renda, educação e longevidade, tornou-se a principal unidade de medida do desenvolvimento a partir de então. Sua criação teve a influência fundamental do economista indiano, então membro da presidência do Banco Mundial, Amartya Sen e suas ideias, que viriam a ser publicadas em duas de suas principais obras, quais sejam, Sobre Ética e Economia e Desenvolvimento como Liberdade, ambas publicadas no ano 1999.

Em Sobre Ética e Economia, Sen (1999) discute a perda da origem ética da economia a partir do momento em que o "bem" deixou de incluir uma pluralidade de aspectos valiosos à vida humana, como satisfações, direitos, liberdades, oportunidades reais, etc., passando a ser interpretado como "bem-estar" e, posteriormente, com a redução deste à "utilidade". Tais discussões serviram de base para sua teoria que interpreta o desenvolvimento como a expansão das liberdades reais de que os indivíduos podem desfrutar.

Em Desenvolvimento como Liberdade, Sen (2010) coloca em xeque a visão simplista que analisava o desenvolvimento apenas sob a ótica da renda, predominante nas interpretações das várias escolas de pensamento econômico. Nessa obra, o autor concentra-se particularmente nos papéis e inter-relações entre certas liberdades instrumentais que considera cruciais, incluindo oportunidades econômicas, liberdades políticas, facilidades sociais, garantias de transparência e segurança protetora. Evidencia, ainda, dentre outras coisas, os descompassos observados entre renda e longevidade em diversos países.

A busca por uma interpretação que abarque, tanto quanto possível, a complexidade que envolve o processo de desenvolvimento levou a uma convergência de ideias que uniu ao desenvolvimento o adjetivo "sustentável". O desenvolvimento sustentável, cuja definição ainda é discutida, tornou-se a tese de diversos autores que buscavam propor alternativas capazes de reunir inclusão social, bem-estar econômico e preservação dos recursos naturais. Um dos expoentes dessa linha teórica é Ignacy Sachs com sua proposta de desenvolvimento includente, sustentável e sustentado.

Sachs (2008, p. 15) destaca que o desenvolvimento sustentável baseia-se "no duplo imperativo ético de solidariedade sincrônica com a geração atual e de solidariedade diacrônica com as gerações futuras". O autor identifica cinco pilares do desenvolvimento sustentável: social, ambiental, territorial, econômico e político. Tendo como uma de suas características partir do concreto e do local para formular teorias universais, Sachs (2009) defende ainda que essa qualidade de desenvolvimento requer um planejamento local e participativo das autoridades locais, da comunidade e de associações de cidadãos, no nível micro. 
Com o avanço das teorias sobre o desenvolvimento, verifica-se que o crescimento econômico passa a ser um instrumento dentre tantos outros, e não um objetivo em si. Nesse ponto, cabe voltar à discussão sobre a medição do desenvolvimento.

Refletir a complexidade abordada nas teorias mais recentes através de números sínteses tornou-se um desafio ainda a ser superado. A criação do IDH representou um avanço, nesses termos, em relação ao extensivo e equivocado uso da renda per capita pelas teorias de desenvolvimento.

No entanto esse índice é amplamente criticado, em especial, devido a sua metodologia privilegiar o efeito da renda sobre os demais indicadores que o compõem. Numa tentativa de superar as limitações do IDH, diversos outros índices foram sendo criados, formando o que Veiga (2010) chama de indicadores de terceira e quarta geração. Esses indicadores e índices mais complexos procuram utilizar-se de dados que representem a multidisciplinariedade e multidimensionalidade que envolvem as teorias de desenvolvimento mais atuais.

$\mathrm{Na}$ falta de um índice que envolva os aspectos mais amplos do desenvolvimento, como a abordagem de Sachs (2008), e que permita a comparação direta dos dois pontos de referência em que se concentra esta pesquisa, utilizou-se um indicador que pode ser caracterizado como de terceira geração. O Índice FIRJAN de Desenvolvimento Municipal (IFDM), assim como o IDH, é composto por indicadores de renda, educação e saúde, ou seja, trata-se de um índice de desenvolvimento socioeconômico. No entanto possui vantagens metodológicas não alcançadas no IDH. Uma breve discussão sobre os aspectos metodológicos do índice são apresentados na próxima seção.

\section{ABORDAGEM METODOLÓGICA}

Para avaliação do desenvolvimento econômico do estado de Mato Grosso, foi utilizado o IFDM, referente aos anos de 2005 e 2013. O IFDM foi criado pela Federação das Indústrias do Estado do Rio de Janeiro (FIRJAN) com o objetivo de mensurar o desenvolvimento socioeconômico dos municípios brasileiros. O índice é calculado sob a ótica das três áreas essenciais do desenvolvimento humano: Educação, Saúde e Emprego \& Renda, possui periodicidade anual, recorte municipal com abrangência dos 5.565 municípios brasileiros e utilizam-se exclusivamente as estatísticas públicas oficiais.

O índice varia de zero a um, sendo que, quanto mais próximo de um, mais desenvolvida é a localidade. Municípios com índice inferior a 0,4 são considerados com baixo desenvolvimento; os que apresentam índices entre 0,4 e 0,6 enquadram-se em desenvolvimento regular; locais em que o índice está entre 0,6 e 0,8 são classificados com desenvolvimento moderado; e, por fim, municípios com índice superior a 0,8 são considerados com alto desenvolvimento.

As vertentes que compõem o índice consolidado do IFDM são obtidas pelas variáveis a seguir e resumidas no Quadro 1:

- Emprego e Renda: esse índice é composto por dois parâmetros: Emprego, que tem por objetivo avaliar a geração de emprego formal e a capacidade de absorção da mão de obra de uma determinada localidade; e Renda que objetiva captar a geração de renda de um determinado município e a forma como essa renda é distribuída no mercado de trabalho. Cada variável possui uma representatividade de $50 \%$ dentro do índice Emprego e Renda. Os dados para esse índice são extraídos da Relação Anual de Informações Sociais (RAIS) e do Cadastro Geral 
de Empregados e Desempregados (CAGED), ambos do Ministério do Trabalho e Emprego, e utilizam-se junto com essas fontes mencionadas, projeções oficiais de população do Instituto Brasileiro de Geografia e Estatística (IBGE). O principal objetivo do índice Emprego \& Renda é detectar a conjuntura econômica do local e consequentemente observar as características estruturais do mercado de trabalho.

- Educação: avalia a qualidade da educação prestada no ensino infantil e fundamental em escolas públicas e privadas. Esse índice é composto por seis indicadores. Para o ensino fundamental, é atribuído peso de $80 \%$, que é distribuído entre cinco indicadores: $55 \%$ para indicadores meio e $25 \%$ para indicadores fim. A educação infantil fica com proporção dos $20 \%$ restantes do índice em razão de seu poder de influenciar a aprendizagem futura e o mercado de trabalho. Os dados do índice são coletados do Instituto Nacional de Estudos e Pesquisas Educacionais Anísio Teixeira (INEP), do Ministério da Educação.

- Saúde: esse índice avalia a saúde básica e contempla indicadores na qual o controle está sob a competência dos municípios. As fontes de dados do índice são o Sistema de Informação sobre Mortalidade (SIM), do Sistema de Informações sobre Nascidos Vivos (Sinasc) e do Sistema Internações Hospitalares (SIH), todos do Departamento de Informática do Sistema Único de Saúde (DataSUS) do Ministério da Saúde. O IFDM saúde é composto por quatro indicadores com pesos iguais ( $25 \%$ cada).

\begin{tabular}{|l|l|l|}
\hline \multicolumn{2}{|c|}{ IFDM } \\
\hline Emprego e Renda & Educação & Saúde \\
\hline Geração de emprego formal & Matrículas na educação infantil & $\begin{array}{l}\text { Número de consultas pré- } \\
\text { natal }\end{array}$ \\
\hline Absorção da mão de obra local & Abandono no ensino fundamental & $\begin{array}{l}\text { Óbitos por causas mal } \\
\text { definidas }\end{array}$ \\
\hline Geração de Renda formal & $\begin{array}{l}\text { Distorção idade- série no ensino } \\
\text { fundamental }\end{array}$ & $\begin{array}{l}\text { Óbitos infantis por causas } \\
\text { evitáveis }\end{array}$ \\
\hline $\begin{array}{l}\text { Salários Médios do emprego } \\
\text { formal }\end{array}$ & $\begin{array}{l}\text { Docentes com o ensino superior no } \\
\text { ensino fundamental }\end{array}$ & $\begin{array}{l}\text { Internação sensível à } \\
\text { atenção básica }\end{array}$ \\
\hline Desigualdade & $\begin{array}{l}\text { Média de horas aula diárias no ensino } \\
\text { fundamental }\end{array}$ & $\begin{array}{l}\text { Resultado do IDEB no ensino } \\
\text { fundamental }\end{array}$ \\
\hline $\begin{array}{l}\text { Fonte: Ministério do Trabalho } \\
\text { e Emprego }\end{array}$ & Fonte: Ministério da Educação & Fonte: Ministério da Saúde \\
\hline
\end{tabular}

Quadro 1- Resumo das variáveis componentes do IFDM por Área de Desenvolvimento Fonte: FIRJAN (2015).

Como o objetivo nesta pesquisa é analisar a relação entre o crescimento e o desenvolvimento no estado de Mato Grosso, adotou-se a estratégia de estabelecer uma comparação entre os resultados do IFDM referente aos anos de 2005 e 2013 e, sobre os dados, aplicar o teste de Mann-Whitney. Dessa forma, é possível verificar se houve avanço significativo, em termos estatísticos, no desenvolvimento socioeconômico no estado e verificar quais aspectos (variáveis do índice) têm contribuído mais, ou menos, para o resultado do estado. Os anos de referência foram escolhidos por serem o primeiro e o último da série disponível para o IFDM.

O teste não paramétrico de Mann-Whitney (também chamado de Wilcoxon rank-sum test ou teste de Wilcoxon-Mann-Whitney) foi desenvolvido primeiramente por F. Wilcoxon em 1945, 
para comparar tendências centrais de duas amostras independentes de tamanhos iguais. Em 1947, H.B. Mann e D.R. Whitney generalizaram a técnica para amostras de tamanhos diferentes. O que o teste ${ }^{4}$ faz é verificar se há evidências para acreditar que valores de um grupo " $A$ " são superiores aos valores do grupo "B".

Para uma melhor compreensão da evolução do desenvolvimento em Mato Grosso, além da aplicação do teste para análise geral, optou-se também por aplicar o teste em cada macrorregião do estado. O objetivo é verificar possíveis discrepâncias entre essas regiões e de que forma podem estar influenciando o resultado em nível estadual. A divisão territorial e os principais polos econômicos das macrorregiões são apresentados no Quadro 2.

\begin{tabular}{|l|c|c|l|}
\hline Macrorregiões & $\begin{array}{c}\text { Qtde } \\
\text { Municípios }\end{array}$ & $\begin{array}{c}\text { Percentual de } \\
\text { Municípios }\end{array}$ & \multicolumn{1}{|c|}{ Polos econômicos } \\
\hline Centro-Sul & 23 & $16 \%$ & Cuiabá, Cáceres e Tangará da Serra \\
\hline Médio-Norte & 16 & $11 \%$ & Sinop, Sorriso e Lucas do Rio Verde \\
\hline Nordeste & 22 & $16 \%$ & Água Boa e Vila Rica \\
\hline Noroeste & 12 & $9 \%$ & Juara e Juína \\
\hline Norte & 17 & $12 \%$ & Alta Floresta e Matupá \\
\hline Oeste & 22 & $16 \%$ & Pontes e Lacerda e Sapezal \\
\hline Sudeste & 29 & $21 \%$ & Rondonópolis, Primavera do Leste e Barra do Garças \\
\hline Mato Grosso & $\mathbf{1 4 1}$ & $\mathbf{1 0 0 \%}$ & Cuiabá e Rondonópolis \\
\hline
\end{tabular}

Quadro 2 - Macrorregiões de Mato Grosso por quantidade de municípios e principais polos econômicos.

Fonte: Adaptado de IMEA (2010).

\section{RESULTADOS E DISCUSSÃO}

\subsection{Crescimento econômico e desenvolvimento em Mato Grosso}

O processo histórico que envolveu avanços tecnológicos e de infraestrutura, bem como a migração de sulistas que detinham conhecimento produtivo de lavouras temporárias, permitiram ao Mato Grosso, a partir da década 1970, tornar-se a fronteira agrícola do país (FARIA, 2014).

Nesse contexto, o estado especializa-se na produção de commodities agrícolas para o mercado internacional, e a base da economia mato-grossense foi consolidada no agronegócio. O estado apresentou vultosa expansão do seu Produto Interno Bruto (PIB) a partir da década de 2000, em especial no triênio 2002-2004 em que o crescimento esteve próximo de $30 \%$ ao ano, porém na sequência houve a crise do setor agrícola nacional no biênio 2005-2006. Mesmo com a referida crise, o estado apresentou uma variação real de $129 \%$ no PIB, no período 2005 a 2013, ao qual esta pesquisa dá ênfase (Quadro 3).

\footnotetext{
${ }^{4}$ Maiores detalhes sobre o teste podem ser encontrados em Bruni (2007).
} 


\begin{tabular}{|l|r|r|r|r|r|r|r|r|r|}
\hline \multirow{2}{*}{ Região } & \multicolumn{3}{|c|}{$\mathbf{2 0 0 5}$} & \multicolumn{3}{|c|}{$\mathbf{2 0 1 3}$} & \multicolumn{2}{|c|}{ Variação (\%) } \\
\cline { 2 - 11 } & PIB (R\$) & População & $\begin{array}{c}\text { PIB per } \\
\text { capita } \\
\text { (R\$) }\end{array}$ & PIB (R\$) & População & $\begin{array}{c}\text { PIB per } \\
\text { capita } \\
\text { (R\$) }\end{array}$ & PIB & População & $\begin{array}{c}\text { PIB } \\
\text { per } \\
\text { capita }\end{array}$ \\
\hline Centro-sul & 12.792 .578 & 1.184 .940 & 10,80 & 25.001 .845 & 1.264 .300 & 19,78 & 95 & 7 & 83 \\
\hline Médio-norte & 5.241 .400 & 276.524 & 18,95 & 7.591 .591 & 392.250 & 19,35 & 45 & 42 & 2 \\
\hline Nordeste & 1.905 .893 & 190.841 & 9,99 & 12.531 .567 & 226.489 & 55,33 & 558 & 19 & 454 \\
\hline Noroeste & 1.541 .803 & 177.390 & 8,69 & 4.169 .249 & 201.157 & 20,73 & 170 & 13 & 138 \\
\hline Norte & 1.872 .269 & 243.913 & 7,68 & 6.233 .452 & 268.308 & 23,23 & 233 & 10 & 203 \\
\hline Oeste & 4.135 .427 & 232.508 & 17,79 & 11.222 .107 & 258.991 & 43,33 & 171 & 11 & 144 \\
\hline Sudeste & 9.976 .567 & 497.158 & 20,07 & 19.056 .388 & 570.618 & 33,40 & 91 & 15 & 66 \\
\hline Mato Grosso & $\mathbf{3 7 . 4 6 5 . 9 3 7}$ & $\mathbf{2 . 8 0 3 . 2 7 4}$ & $\mathbf{1 3}$ & $\mathbf{8 5 . 8 0 6 . 1 9 8}$ & $\mathbf{3 . 1 8 2 . 1 1 3}$ & $\mathbf{2 7}$ & $\mathbf{1 2 9}$ & $\mathbf{1 4}$ & $\mathbf{1 0 2}$ \\
\hline
\end{tabular}

Quadro 3- Produto Interno Bruto (PIB)*, população** e PIB per capita* de Mato Grosso e suas macrorregiões em 2005 e 2013

* Em mil reais. Os valores do ano 2013 foram deflacionados com base 2005 igual a 100.

**Estimativas populacionais para os municípios brasileiros enviadas ao TCU para cálculo das cotas do Fundo de Participação dos Estados e Municípios e para áreas propostas para constituição de novos municípios e distritos, bem como dos municípios já existentes que alterem seus limites, em atendimento a dispositivos legais.

Fonte: Elaboração própria (IBGE, 2005; 2013).

Não obstante, uma análise mais cuidadosa para se identificar o crescimento de uma economia deve levar em consideração o crescimento populacional do território em questão. Assim, o indicador mais utilizado nas análises de crescimento econômico é o PIB per capita. Com um crescimento populacional acumulado de apenas 14\% entre 2005 e 2013, a renda per capita de Mato Grosso cresceu 102\% em termos reais, saltando de R\$ 13 mil em 2005 para R\$ 27 mil em 2013.

Tal crescimento não aconteceu de maneira homogênea entre as regiões do estado (Quadro 3). Dentre elas, quatro obtiveram crescimento da renda per capita acima de 100\%-nordeste, noroeste, norte e oeste-, com destaque para região nordeste que acumulou um crescimento de $454 \%$ no período. As regiões centro-sul e sudeste, que possuem as duas maiores cidades-polo do estado (Cuiabá e Rondonópolis) ${ }^{5}$, tiveram crescimento do PIB per capita de 83\% e 66\%, respectivamente. Apenas a região médio-norte não cresceu no nível das demais, tendo apresentado o menor crescimento do PIB e o maior crescimento populacional do estado, com uma expansão de apenas 2\% em termos per capita, entre 2005 e 2013.

No Quadro 4, é possível encontrar uma evidência da razão do crescimento econômico observado nas regiões. Trata-se da expansão da atividade agrícola, aqui indicada pelo aumento da área plantada de lavouras temporárias, de modo geral, e de maneira mais específica pelo aumento da quantidade produzida de soja (principal produto da pauta de exportação de Mato Grosso). A área plantada de lavouras temporárias cresceu em todas as macrorregiões, com destaque para região nordeste com incremento de 106,77\%, e as regiões médio-norte, noroeste e norte próximas de 50\%. Em relação à quantidade produzida de soja, fica evidente a intensa

\footnotetext{
${ }^{5}$ Apesar de Cuiabá e Rondonópolis serem as duas maiores economias municipais de Mato Grosso, um estudo realizado por Faria, Azevedo Junior e Dassow (2015) evidencia uma mudança potencial na polarização dos municípios matogrossenses. Os resultados do estudo mostraram que, em quatro municípios da região sudeste, quatro da região centro-sul, quatro da região médio-norte e dois na região oeste possuem potencial para tornarem-se cidades-polo, com redução da importância relativa de Cuiabá e Rondonópolis.
} 
expansão da cultura sobre as regiões nordeste $(153,2 \%)$ e norte $(217,3 \%)$, consideradas como fronteira agrícola dentro do estado. Apenas a região oeste apresentou redução na quantidade produzida de soja.

\begin{tabular}{|l|r|r|r|r|r|r|}
\hline \multirow{2}{*}{ Macrorregião } & \multicolumn{2}{|c|}{ Área plantada (Ha) } & \multicolumn{2}{c|}{ Quant. produção soja (T) } & \multicolumn{2}{c|}{ Variação (\%) } \\
\cline { 2 - 7 } & $\mathbf{2 0 0 5}$ & $\mathbf{2 0 1 3}$ & $\mathbf{2 0 0 5}$ & $\mathbf{2 0 1 3}$ & $\begin{array}{c}\text { Área } \\
\text { plantada } \\
\text { (Ha) }\end{array}$ & $\begin{array}{c}\text { Quant. } \\
\text { produção } \\
\text { soja (T) }\end{array}$ \\
\hline Centro Sul & $843.262,00$ & $940.443,00$ & $1.481 .002,00$ & $1.501 .386,00$ & 11,52 & 1,38 \\
\hline Médio Norte & $3.148 .722,00$ & $4.796 .128,00$ & $6.898 .416,00$ & $8.782 .621,00$ & 52,32 & 27,31 \\
\hline Nordeste & $702.861,00$ & $1.453 .332,00$ & $1.283 .923,00$ & $3.250 .973,00$ & 106,77 & 153,21 \\
\hline Noroeste & $453.665,00$ & $687.831,00$ & $811.751,00$ & $1.280 .377,00$ & 51,62 & 57,73 \\
\hline Norte & $173.282,00$ & $258.894,00$ & $158.846,00$ & $504.072,00$ & 49,41 & 217,33 \\
\hline Oeste & $1.395 .534,00$ & $1.787 .847,00$ & $3.040 .282,00$ & $2.999 .392,00$ & 28,11 & $-1,34$ \\
\hline Sudeste & $2.259 .368,00$ & $2.799 .015,00$ & $4.087 .224,00$ & $5.097 .953,00$ & 23,88 & 24,73 \\
\hline Mato Grosso & $\mathbf{8 . 9 7 6 . 6 9 4 , 0 0}$ & $\mathbf{1 2 . 7 2 3 . 4 9 0 , 0 0}$ & $\mathbf{1 7 . 7 6 1 . 4 4 4 , 0 0}$ & $\mathbf{2 3 . 4 1 6 . 7 7 4 , 0 0}$ & $\mathbf{4 1 , 7 4}$ & $\mathbf{3 1 , 8 4}$ \\
\hline
\end{tabular}

Quadro 4 - Área plantada de lavoura temporária e quantidade produzida de soja em Mato Grosso e suas macrorregiões em 2005 e 2013

Fonte: Elaboração própria (IBGE, 2005; 2013).

Alternativamente, um indicador que pode ser utilizado com a finalidade de identificar os setores que estejam impulsionando a atividade econômica em determinada localidade é a quantidade de empregos gerados por cada atividade. A variação da quantidade de empregados (formais) por setor de atividade em Mato Grosso e suas macrorregiões são apresentados no Quadro 5. Observa-se que o maior crescimento, em termos percentuais, ocorreu no setor de construção civil em todas as macrorregiões mato-grossenses.

\begin{tabular}{|l|c|c|c|c|c|c|}
\hline \multirow{2}{*}{\multicolumn{1}{|c|}{ Macrorregião }} & \multicolumn{7}{|c|}{ Variação (\%) } \\
\cline { 2 - 7 } & Indústria & Construção Civil & Comércio & Serviços & Agropecuária & Total \\
\hline Centro-sul & 50 & 208 & 58 & 29 & 40 & 44 \\
\hline Médio-norte & 61 & 409 & 108 & 103 & 91 & 99 \\
\hline Nordeste & 50 & 111 & 113 & 62 & 92 & 79 \\
\hline Noroeste & 37 & 519 & 103 & 87 & 112 & 80 \\
\hline Norte & 54 & 4565 & 82 & 87 & 98 & 104 \\
\hline Oeste & 37 & 300 & 80 & 80 & 71 & 71 \\
\hline Sudeste & 119 & 147 & 74 & 68 & 22 & 66 \\
\hline Mato Grosso (Total) & $\mathbf{6 0}$ & $\mathbf{2 6 1}$ & $\mathbf{7 4}$ & $\mathbf{4 6}$ & $\mathbf{5 7}$ & $\mathbf{6 2}$ \\
\hline
\end{tabular}

Quadro 5 - Variação no número de empregos por setor de atividade em Mato Grosso e suas macrorregiões entre 2005 e 2013

Fonte: Elaboração própria (RAIS/CAGED, 2005; 2013).

O setor industrial foi o que apresentou uma das menores variações entre os setores de atividade analisados. No entanto cabe destacar o crescimento de $119 \%$ no número de empregados nesse setor na região sudeste, na qual se encontra o município de Rondonópolis, cuja produção industrial é comparável ao da capital Cuiabá, em termos de Valor Adicionado Bruto (VAB). O setor de comércio apresentou expansão maior no número de empregados nas regiões médio-norte, nordeste e noroeste, e o setor de serviços apresentou maior variação percentual 
na região médio-norte. Por fim, o número de empregados no setor agropecuário variou próximo de $90 \%$ nas regiões médio-norte, nordeste e norte, e mais que $100 \%$ na região noroeste.

Conforme discutido na introdução deste artigo, a relação entre o crescimento econômico e o processo de desenvolvimento nem sempre acontece de forma simétrica. Em vista disso, propõe-se o uso de uma medida que considere uma gama maior de indicadores que envolvam outras variáveis além da renda. O IFDM contempla indicadores de saúde e educação, além da vertente de Emprego \& Renda, com a vantagem de ser divulgado anualmente.

Entre os anos de 2005 e 2013, é possível identificar uma melhoria no IFDM dos municípios mato-grossenses, conforme apontado na Figura 1. No ano de 2005, a maior parte (66\%) dos municípios era considerada como desenvolvimento regular (índice entre 0,4 e 0,6), 7\% eram considerados de baixo desenvolvimento, com índice abaixo de 0,4 , e nenhum município atingiu grau de desenvolvimento alto (acima de 0,8 ), ficando os mais desenvolvidos (28\%) enquadrados na categoria de desenvolvimento moderado (índice entre 0,6 e 0,8).

$2005-2013$

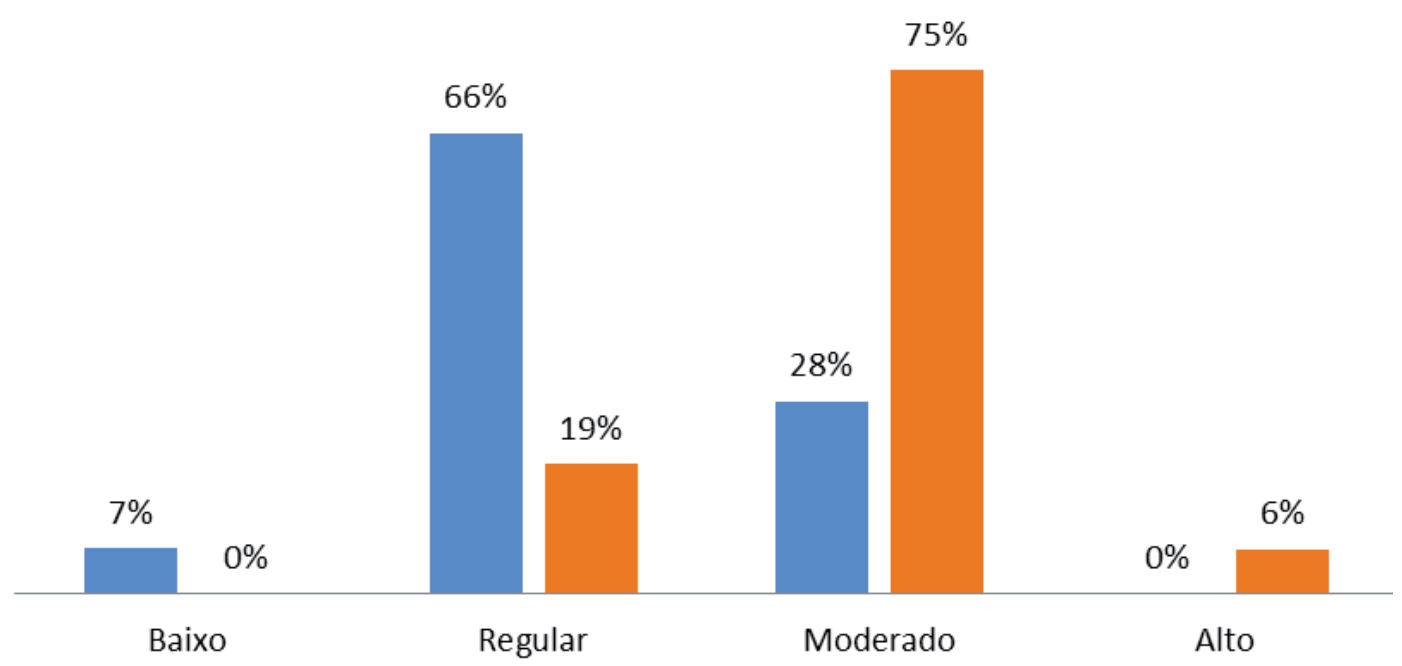

Figura 1 - Distribuição dos municípios de Mato Grosso por grau de desenvolvimento nos anos de 2005 e 2013

Fonte: Elaboração própria (FIRJAN, 2005; 2013).

Em 2013, observa-se uma mudança nos pontos extremos. Nenhum município foi classificado como baixo desenvolvimento, e nove municípios alcançaram um índice de alto desenvolvimento (6\%). A maior parte dos municípios deixou a classificação de desenvolvimento regular e evoluiu para desenvolvimento moderado (75\%), saltando de 38, em 2005, para 105 municípios, em 2013.

Torna-se relevante, ainda, identificar a distribuição espacial dos graus de desenvolvimento dos municípios mato-grossenses. Essa distribuição pode ser observada no Quadro 6. Identifica-se que seis dos nove municípios que passaram a figurar na classificação de alto desenvolvimento, segundo o IFDM, estavam localizados na região médio-norte do estado. Os outros três encontram-se nas regiões sudeste (dois) e oeste (um). No grupo em que se obteve maior acréscimo, desenvolvimento moderado, verificam-se avanços significativos em termos de quantidade de municípios em todas as regiões, com exceção apenas da região médio-norte que manteve o quantitativo. 


\begin{tabular}{|l|c|c|c|c|c|c|c|c|}
\hline \multirow{2}{*}{ Macrorregião } & \multicolumn{2}{|c|}{ Alto } & \multicolumn{2}{c|}{ Moderado } & \multicolumn{2}{c|}{ Regular } & \multicolumn{2}{c|}{ Baixo } \\
\cline { 2 - 9 } & $\mathbf{2 0 0 5}$ & $\mathbf{2 0 1 3}$ & $\mathbf{2 0 0 5}$ & $\mathbf{2 0 1 3}$ & $\mathbf{2 0 0 5}$ & $\mathbf{2 0 1 3}$ & $\mathbf{2 0 0 5}$ & $\mathbf{2 0 1 3}$ \\
\hline Centro-sul & 0 & 0 & 4 & 21 & 17 & 2 & 2 & 0 \\
\hline Médio-norte & 0 & 6 & 10 & 10 & 4 & 0 & 0 & 0 \\
\hline Nordeste & 0 & 0 & 2 & 9 & 13 & 13 & 7 & 0 \\
\hline Noroeste & 0 & 0 & 1 & 9 & 11 & 2 & 0 & 0 \\
\hline Norte & 0 & 0 & 3 & 14 & 13 & 3 & 0 & 0 \\
\hline Oeste & 0 & 1 & 7 & 20 & 15 & 1 & 0 & 0 \\
\hline Sudeste & 0 & 2 & 11 & 22 & 18 & 5 & 0 & 0 \\
\hline Mato Grosso & $\mathbf{0}$ & $\mathbf{9}$ & $\mathbf{3 8}$ & $\mathbf{1 0 5}$ & $\mathbf{9 1}$ & $\mathbf{2 6}$ & $\mathbf{9}$ & $\mathbf{0}$ \\
\hline
\end{tabular}

Quadro 6 - Quantidade de municípios* por grau de desenvolvimento nas macrorregiões de Mato Grosso nos anos de 2005 e 2013

*Em 2005, três municípios não foram contabilizados por falta de dados; em 2013, pelo mesmo motivo um município não foi contabilizado.

Fonte: Elaboração própria (FIRJAN, 2005; 2013).

Na categoria de desenvolvimento regular, quase todas as regiões reduziram a quantidade de municípios. A exceção foi a região nordeste, que manteve 13 municípios nessa categoria, mas que, por outro lado, eliminou os sete que estavam classificados como baixo desenvolvimento. Cabe destacar, ainda, que a região médio-norte, no ano de 2013, deixa de ter municípios nas duas classificações mais baixas do IFDM, quais sejam desenvolvimentos regular e baixo.

No Quadro 7, além do comparativo do IFDM consolidado por região nos dois anos avaliados nesse estudo, são apresentadas também as três vertentes que compõem o índice, ou seja, Emprego \& Renda, Educação e Saúde. De modo geral, o que se observa é que a vertente que obteve maior variação no período, no nível agregado (estadual), foi a de Educação, que saltou de um índice de 0,496 para 0,751, ou seja, evoluiu da categoria de desenvolvimento regular para moderado. Na vertente Emprego \& Renda, a melhoria do índice não foi suficiente para elevar o grau de desenvolvimento no período, mantendo-se na categoria de desenvolvimento regular. A vertente de Saúde também não mudou de categoria, mas o grau de desenvolvimento está em um nível acima (moderado).

\begin{tabular}{|l|c|c|c|c|c|c|c|c|}
\hline \multirow{2}{*}{ Região } & \multicolumn{2}{|c|}{ Consolidado } & \multicolumn{2}{c|}{ Emprego \& Renda } & \multicolumn{2}{c|}{ Educação } & \multicolumn{2}{c|}{ Saúde } \\
\cline { 2 - 10 } & $\mathbf{2 0 0 5}$ & $\mathbf{2 0 1 3}$ & $\mathbf{2 0 0 5}$ & $\mathbf{2 0 1 3}$ & $\mathbf{2 0 0 5}$ & $\mathbf{2 0 1 3}$ & $\mathbf{2 0 0 5}$ & $\mathbf{2 0 1 3}$ \\
\hline Centro-sul & 0,526 & 0,671 & 0,464 & 0,538 & 0,509 & 0,749 & 0,606 & 0,726 \\
\hline Médio-norte & 0,642 & 0,763 & 0,581 & 0,646 & 0,565 & 0,800 & 0,780 & 0,842 \\
\hline Nordeste & 0,468 & 0,591 & 0,425 & 0,529 & 0,408 & 0,692 & 0,572 & 0,552 \\
\hline Noroeste & 0,538 & 0,668 & 0,446 & 0,498 & 0,465 & 0,736 & 0,702 & 0,770 \\
\hline Norte & 0,541 & 0,675 & 0,462 & 0,552 & 0,477 & 0,774 & 0,691 & 0,699 \\
\hline Oeste & 0,562 & 0,685 & 0,517 & 0,532 & 0,512 & 0,755 & 0,657 & 0,768 \\
\hline Sudeste & $\mathbf{0 , 5 7 4}$ & 0,683 & 0,504 & 0,575 & 0,531 & 0,758 & 0,688 & 0,717 \\
\hline Mato Grosso & $\mathbf{0 , 5 4 7}$ & $\mathbf{0 , 6 7 4}$ & $\mathbf{0 , 4 8 5}$ & $\mathbf{0 , 5 5 4}$ & $\mathbf{0 , 4 9 6}$ & $\mathbf{0 , 7 5 1}$ & $\mathbf{0 , 6 6 2}$ & $\mathbf{0 , 7 1 7}$ \\
\hline
\end{tabular}

Quadro 7 - Média* do IFDM no estado de Mato Grosso e suas macrorregiões nos anos 2005 e 2013 *O cálculo das média leva em conta o índice dos municípios que formam o território (macrorregiões/estado). Fonte: Elaboração própria (FIRJAN, 2005; 2013). 
Em relação às regiões, na vertente Emprego \& Renda, a única que evoluiu da classificação de desenvolvimento regular foi a médio-norte, que passou a figurar na categoria de desenvolvimento moderado. Na vertente Educação, todas as regiões saltaram da categoria de desenvolvimento regular para moderado. E, na vertente Saúde, todas as regiões se mantiveram no nível de desenvolvimento moderado, com exceção também da região médio-norte, que foi a única a evoluir para alto desenvolvimento.

A fim de obter maior segurança em relação à evolução do índice de desenvolvimento no estado e suas regiões, aplicou-se um teste não-paramétrico para identificar a significância estatística dessa evolução. Os resultados encontram-se no Quadro 8. Recapitulando, o procedimento consiste em testar a hipótese nula de que não há diferença estatisticamente significativa nas médias do índice no ano de 2013 em relação a 2005. Para simplificar a observação dos resultados, optou-se por apresentar a estatística p-value ao invés da estatística Zcal.

\begin{tabular}{|l|c|c|c|c|}
\hline \multicolumn{1}{|c|}{ Região } & Consolidado & Emprego \& Renda & Educação & Saúde \\
\hline Centro-sul & 0,0000 & 0,0379 & 0,0000 & 0,0004 \\
\hline Médio-norte & 0,0005 & 0,2617 & 0,0000 & 0,0460 \\
\hline Nordeste & 0,0001 & 0,0092 & 0,0000 & 0,8510 \\
\hline Noroeste & 0,0005 & 0,2184 & 0,0000 & 0,0647 \\
\hline Norte & 0,0000 & 0,0105 & 0,0000 & 0,9588 \\
\hline Oeste & 0,0000 & 0,6899 & 0,0000 & 0,0006 \\
\hline Sudeste & 0,0000 & 0,0338 & 0,0000 & 0,4054 \\
\hline Mato Grosso & $\mathbf{0 , 0 0 0 0}$ & $\mathbf{0 , 0 0 0 0}$ & $\mathbf{0 , 0 0 0 0}$ & $\mathbf{0 , 0 0 0 1}$ \\
\hline$H_{0}:$ Índice 2013 = Índice 2005
\end{tabular}

Quadro 8 - Resultados ( $p$-value) do teste de Mann-Whitney sobre o IFDM em Mato Grosso e suas macrorregiões

Fonte: Dados da pesquisa.

No nível estadual, apesar de não ter havido mudança nas vertentes de Emprego \& Renda e Saúde suficiente para mudar a categoria de desenvolvimento, todas as categorias apresentaram aumento estatisticamente significativo. No nível regional, o índice consolidado e o de Educação mostrou evolução estatisticamente significativa em todas. O mesmo não pode ser afirmado para as vertentes de Emprego \& Renda e Saúde. Considerando um nível de significância de 5\%, na vertente Emprego \& Renda, o resultado do teste nas regiões médio-norte, noroeste e oeste aponta que não é possível rejeitar a hipótese nula, ou seja, não há evidências de que a média regional do índice em 2013 seja superior ao índice em 2005. Na vertente Saúde, a hipótese nula não é rejeitada nas regiões nordeste, noroeste, norte e sudeste, considerando o mesmo nível de significância.

Cabe salientar, no entanto, que, apesar de o teste não ter rejeitado, a hipótese nula na região médio-norte para a vertente de Emprego \& Renda, esta foi a única que figurou no grau de desenvolvimento moderado. De modo semelhante, na vertente Saúde, apesar de quatro das sete regiões não apresentarem diferença estatisticamente significativa na variação do índice, o nível de desenvolvimento é moderado ou alto. 


\section{CONSIDERAÇÕES FINAIS}

A análise dos indicadores de crescimento econômico demonstrou que o vertiginoso crescimento de $102 \%$ da renda per capita no estado de Mato Grosso refletiu em desenvolvimento sob a ótica do índice utilizado, tendo saltado da categoria de desenvolvimento regular para moderado.

Analisando as vertentes que compõem o índice, no entanto, foi possível verificar que, apesar de todas terem evolução estatisticamente significativa, a vertente de Educação foi a que mais contribuiu para a melhoria no índice do estado. Cabe destacar que a vertente de Emprego \& Renda, que deveria, em tese, ter sido a mais afetada pelo expressivo crescimento econômico, permaneceu na categoria de desenvolvimento regular, o segundo na escala de classificação. Ou seja, tanto a melhoria na educação, quanto o crescimento econômico não foram capazes de elevar consideravelmente as condições de geração de emprego e geração/distribuição de renda no estado, nos anos analisados pela pesquisa.

Quando a análise focalizou o comportamento das variáveis nas regiões, constatou-se a heterogeneidade tanto no crescimento quanto no desenvolvimento. As regiões noroeste e oeste, apesar de terem acumulado um crescimento de $138 \%$ e 144\%, respectivamente, não apresentaram evolução estatisticamente significativa no índice de Emprego \& Renda entre 2005 e 2013. Tornou-se evidente também que o avanço em termos de crescimento econômico nas regiões nordeste, norte e noroeste foi impulsionado pelo aumento da área plantada de lavouras temporárias, em especial de soja.

Esse dado chama atenção para a questão ambiental, visto que esses territórios são compostos por áreas de floresta amazônica e vegetação de transição entre a Amazônia e o Cerrado, e revela a limitação do índice utilizado na pesquisa para uma análise mais completa da situação do desenvolvimento no estado. O cuidado que se deve ter é evitar a consideração dos indicadores socioeconômicos de desenvolvimento sem considerar as possíveis perdas de biodiversidade e serviços ecossistêmicos existentes em um território. Cabe salientar que, somente em 2012, foi aprovado o projeto de lei, que tramitava no legislativo nacional, desde 1999, conhecido como "Novo Código Florestal" brasileiro, que delibera sobre as áreas de preservação permanente, áreas de uso restrito, da exploração florestal e desmatamento, dentre outras coisas. Além disso, destaca-se também a dificuldade de se estabelecer e fazer valer o Zoneamento Socioeconômico e Ecológico (ZSEE) nos estados abrangidos pela Amazônia, inclusive Mato Grosso.

Destacaram-se também, de modo especial, duas regiões por razões opostas. Por um lado, a região médio-norte no eixo da BR-163 mostrando-se como a mais desenvolvida do estado, em termos socioeconômicos. Essa região, apesar de ter acumulado um crescimento da renda per capita muito inferior às demais (2\%), abrange seis dos nove municípios classificados como alto desenvolvimento e não tem mais nenhum município nas duas classificações mais baixas do índice. É a única região que ficou classificada como desenvolvimento moderado na vertente de Emprego \& Renda e a única a ser classificada como alto desenvolvimento nas vertentes de Educação e de Saúde.

No lado oposto, encontra-se a região nordeste no eixo da BR-158. Essa região acumulou um crescimento econômico de 454\%, em termos de renda per capita, que não refletiu em melhorias na geração de emprego e geração e distribuição de renda no mesmo período. Evoluiu muito em educação, como todo o estado, mas foi a única que piorou as condições avaliadas pela vertente Saúde. O avanço maior foi a mudança de sete municípios que eram classificados como baixo desenvolvimento em 2005 e que passaram para desenvolvimento regular em 2013. 
Diante do exposto, cabem ainda algumas considerações. As mais importantes estão relacionadas com as limitações da avaliação do desenvolvimento por meio de números sintéticos (índices), visto que não são capazes de refletir toda complexidade envolvida nesse tema. Por exemplo, não é possível identificar o que tem levado a padrões de desenvolvimento tão opostos como os das regiões nordeste e médio-norte sem um estudo aprofundado das questões históricas e institucionais que envolvem as duas regiões.

No mais, o estudo evidenciou o persistente descompasso, ou defasagem, entre o crescimento econômico e seu reflexo em termos de melhoria para a sociedade, de modo geral. Não ocorreu o transbordamento (tricke-down-effect), no qual o desenvolvimento viria como decorrência natural do crescimento econômico, como presume a teoria econômica predominante.

Questiona-se, dessa forma, o modelo de desenvolvimento adotado por Mato Grosso, enquanto produtor e exportador de commodities agrícolas, que o tornou demasiadamente vulnerável às intempéries dos mercados internacionais. Isso, sem mencionar a dependência tecnológica, visto que a produção agrícola do estado torna-se inviável caso haja um estancamento da capacidade de importar (máquinas, equipamentos, peças, defensivos, fertilizantes, combustíveis, etc.) dos produtores rurais. Questiona-se o modelo de desenvolvimento concentrador de renda, que ameaça as riquezas naturais do estado. Não se pretende sugerir também a adoção do modelo industrialista, adotado por outros estados brasileiros, visto que os problemas apenas mudariam sua forma e funcionalidade.

Cabe considerar seriamente a adoção de modelos de desenvolvimento alternativos, sugeridos na teoria econômica mais recente, como o desenvolvimento sustentável, por exemplo. Propõese considerar as propostas de Sachs $(2008 ; 2009)$ que contemplam a inclusão social por meio da oportunidade de trabalho decente para todos e da gestão negociada e contratual dos recursos.

Propõe-se uma reflexão sobre a relação entre os caminhos do crescimento econômico do estado e a expansão das liberdades substantivas de seus habitantes, na linha do pensamento de Sen (2010). As pessoas que vivem hoje em Mato Grosso tem tido cada vez mais a oportunidade de levar a cabo o tipo de vida que gostariam? E as próximas gerações? Trata-se da questão ética de "solidariedade sincrônica com a geração atual e de solidariedade diacrônica com as gerações futuras", pertinentemente exposta por Sachs (2008, p. 15). Desenvolver sim, de qualquer forma não.

\section{REFERÊNCIAS}

BRUNI, Adriano Leal. Estatística aplicada à gestão empresarial. São Paulo: Atlas, 2007.

FARIA, Alexandre Magno de Melo. Perspectivas para o desenvolvimento de Mato Grosso. In: CAVALCANTI, Isabel Machado et al. (Org.). Um olhar territorial para o desenvolvimento: Centro-Oeste. Rio de Janeiro: BNDES, 2014. p. 394-423.

FARIA, Alexandre Magno de Melo; AZEVEDO JUNIOR, Wladimir Colman de; DASSOW, Charline. Desenvolvimento Territorial desequilibrado e subpolos emergentes em Mato Grosso. Geografares, n. 20, p. 65-78, 2015.

FEDERAÇÃO DAS INDÚSTRIAS DO ESTADO DO RIO DE JANEIRO (FIRJAN). Índice FIRJAM de Desenvolvimento Municipal (IFDM), 2015. Disponível em: <http://www.firjan.org.br/ifdm/downloads/>. Acesso em: 20 abr. 2016.

INSTITUTO BRASILEIRO DE GEOGRAFIA E ESTATÍSTICA (IBGE). Estimativa de Populacionais dos Municípios Brasileiros. 2005 e 2013. Disponível em: < http://www.ibge.gov.br/home/estatistica/populacao/ estimativa2013/>. Acesso em: 20 abr. 2016. 
.Produção Agrícola Municipal. 2005 e 2013. Disponível em: <http://www.sidra.ibge.gov.br/bda/ pesquisas/pam/default.asp?o=29\&i=P>. Acesso em: 20 abr. 2016.

. Produto Interno Bruto dos municípios. 2005 e 2013. Disponível em: <http://www.sidra.ibge.gov.

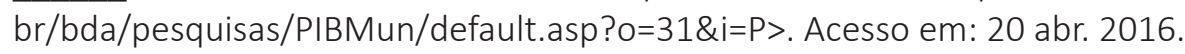

INSTITUTO MATOGROSSENSE DE ECONOMIA AGROPECUÁRIA (IMEA). Mapa de macrorregiões do IMEA. 2010. Disponível em: <http://www.imea.com.br/upload/publicacoes/arquivos/justificativamapa.pdf>. Acesso em: 28 abr. 2016.

RELAÇÃO ANUAL DE INFORMAÇÕES SOCIAIS (RAIS). Rais Vínculo. 2005 e 2013. Disponível em: <http:// bi.mte.gov.br/bgcaged/login.php>. Acesso em: 20 abr. 2016.

SACHS, Ignacy. Desenvolvimento includente, sustentável, sustentado. Rio de Janeiro: Garamond, 2008 .

Caminhos para o desenvolvimento sustentável. Rio de Janeiro: Garamond, 2009.

SEN, A. Sobre economia e ética. 1. ed. São Paulo: Companhia das Letras, 1999.

. Desenvolvimento como liberdade. 5. ed. São Paulo: Companhia das Letras, 2010.

SCHUMPETER, Joseph A. Teoria do Desenvolvimento Econômico: uma investigação sobre lucros, capital, crédito, juro e o ciclo econômico. São Paulo: Nova Cultura, 1997. (Os Economistas).

VEIGA, José Eli da. Desenvolvimento sustentável: o desafio do século XXI. Rio de Janeiro: Garamond, 2010.

\section{Sobre os autores:}

Nagela Bueno Santos: Mestre em Economia e Economista pela Universidade Federal de Mato Grosso (UFMT). E-mail: nagelabueno@hotmail.com

Alexandre Magno de Melo Faria: Pós-doutor em Gestão e Economia pela Universidade da Beira Interior (UBI/Portugal), mestre e doutor em Desenvolvimento Socioambiental pela Universidade Federal do Pará (NAEA/UFPA) e Economista pela UFMT. Professor Associado da Faculdade de Economia da UFMT, Campus Cuiabá. E-mail: dr.melofaria@gmail.com

Dilamar Dallemole: Pós-Doutor em Economia (UBI/Portugal), Doutor em Ciências Agrárias pela Universidade Federal Rural da Amazônia (UFRA) e Economista pela Universidade Regional do Noroeste do Estado do Rio Grande do Sul (UNIJUÍ). Professor Associado da Faculdade de Economia da UFMT, Campus Cuiabá. E-mail: ddallemole@gmail.com

José Ramos Pires Manso: Doutor em Economia, Mestre em Economia da Energia e Licenciado em Economia pelo ISEG da Universidade Técnica de Lisboa. Professor Catedrático do Departamento de Gestão e Economia da Universidade da Beira Interior, Portugal. E-mail: p.manso@ubi.pt 